\title{
Influence of prior walking on postprandial lipaemia in South Asian and White European women
}

\author{
M.J. Roberts ${ }^{1,2}$, A.E. Thackray ${ }^{1,2}$, J.A. King ${ }^{1,2}$, D. Webb ${ }^{2,3}$ and D.J. Stensel ${ }^{1,2}$ \\ ${ }^{1}$ National Centre for Sport and Exercise Medicine, School of Sport, Exercise and Health Sciences, Loughborough \\ University, LE11 3TU, \\ ${ }^{2}$ National Institute for Health Research (NIHR) Leicester Biomedical Research Centre, Leicester, United Kingdom \\ and \\ ${ }^{3}$ Leicester Diabetes Centre, University Hospitals of Leicester and University of Leicester, United Kingdom.
}

South Asians represent the largest ethnic minority in the United Kingdom and have a markedly higher risk of coronary heart disease (CHD) and type 2 diabetes $\left[{ }^{1}\right]$. Previous evidence suggests that South Asian men exhibit impaired postprandial metabolism, but acute bouts of walking and running appear equally, if not more, efficacious for improving postprandial CHD markers in South Asian than white European men $\left[^{2}\right]$. However, it is not known whether similar responses are observed in women.

Twelve healthy South Asian and 12 healthy white European premenopausal women matched for age and body composition (Table 1) completed two, 2-day trials in a counterbalanced, crossover design during the follicular phase of the menstrual cycle. On day 1, participants either rested (control) or completed a treadmill walk for 60 minutes at $\sim 60 \%$ maximal oxygen uptake (exercise). On day 2, participants rested and consumed two high-fat meals over a 9-hour period and 13 venous blood samples were collected to determine concentrations of fasting and postprandial triacylglycerol and glucose.

Table 1.

\begin{tabular}{|c|c|c|c|c|c|c|}
\hline \multirow[b]{2}{*}{ Variable } & \multicolumn{2}{|c|}{$\begin{array}{l}\text { South Asians } \\
\quad(n=12) \\
\end{array}$} & \multicolumn{2}{|c|}{$\begin{array}{l}\text { White Europeans } \\
\qquad(n=12)\end{array}$} & \multirow{2}{*}{$\begin{array}{c}95 \% \text { CI } \\
\text { WE vs. SA }\end{array}$} & \multirow[b]{2}{*}{$\mathrm{P}$ Value } \\
\hline & Mean & $\overline{\mathrm{SD}}$ & Mean & $\overline{\mathrm{SD}}$ & & \\
\hline Age (years) & 24.2 & 6.2 & 24.3 & 5.3 & -5.1 to 4.8 & 0.945 \\
\hline Body mass index $\left(\mathrm{kg} \cdot \mathrm{m}^{-2}\right)$ & 23.3 & 3.8 & 23.9 & 4.0 & -3.9 to 2.7 & 0.700 \\
\hline Body fat $(\%)^{1}$ & 31.1 & 7.3 & 30.9 & 5.3 & -5.6 to 5.9 & 0.944 \\
\hline Visceral adipose tissue $(\mathrm{L})^{2}$ & 1.14 & 0.93 & 0.88 & 0.27 & -0.40 to 0.83 & 0.469 \\
\hline Maximal oxygen uptake $\left(\mathrm{mL} \cdot \mathrm{kg}^{-1} \cdot \mathrm{min}^{-1}\right)$ & 34.8 & 5.1 & 40.5 & 8.5 & -11.6 to 0.3 & 0.060 \\
\hline
\end{tabular}

${ }^{1}$ Determined by bioelectrical impedance; ${ }^{2}$ determined by Magnetic Resonance Imaging.
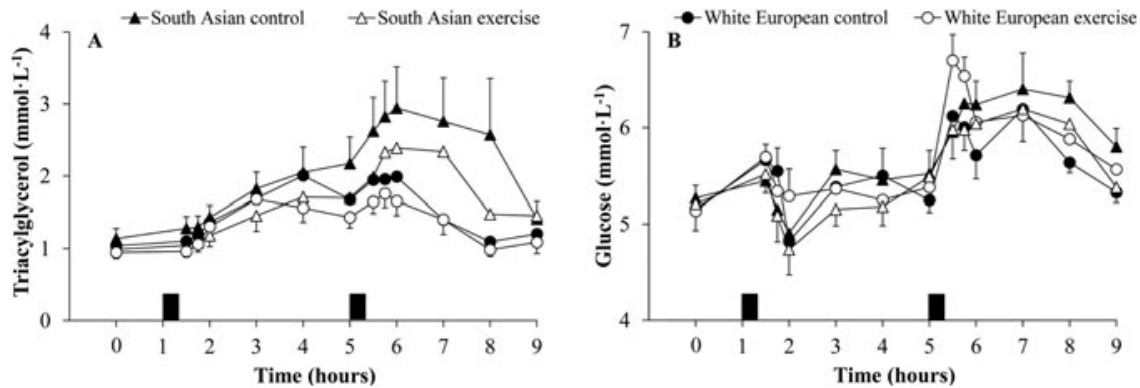

Fig. 1. Mean (SEM) postprandial plasma triacylglycerol (panel A) and glucose (panel B) concentrations in the exercise and control trials for South Asian $(n=10)$ and white European $(n=9)$ women. Black rectangles indicate consumption of breakfast and lunch meals.

Based on ratios of the geometric means ( $95 \%$ CI for ratios), postprandial triacylglycerol concentrations were $18 \%$ higher in South Asian than white European women $(-17$ to $69 \%, \mathrm{ES}=0.34, \mathrm{P}=0.336)$, and $13 \%$ lower after exercise than control $(-16$ to $-10 \%$, ES $=$ $0.29, \mathrm{P}<0.001)$. The exercise-induced reduction in postprandial triacylglycerol concentrations was greater in the South Asian than white European women $(19 \%(\mathrm{ES}=0.40)$ vs $8 \%(\mathrm{ES}=0.17)$, respectively; ethnicity-by-trial interaction $\mathrm{P}<0.001)$. Postprandial glucose concentrations were similar between trials $(P=0.875)$ and ethnic groups $(P=0.845)$, but the magnitude of change after exercise was marginally, albeit significantly, different between the South Asian and white European women $(-3 \%(\mathrm{ES}=0.21)$ vs. $3 \%(\mathrm{ES}=$ 0.20 ), respectively; ethnicity-by-trial interaction $\mathrm{P}=0.005)$.

In conclusion, healthy South Asian women exhibited higher postprandial triacylglycerol concentrations after high fat meals of small-to-moderate magnitude, but acute brisk walking reduced postprandial lipaemia more in South Asian than white European women.

1. Blackledge HM, Newton J, Squire IB (2003) BMJ 327, 526-531.

2. Gholap N, Davies M, Patel K, Sattar N, Khunti K (2011) Prim Care Diabetes. 1, 45-56.

3. Arjunan SP, Bishop NC, Reischak-Oliviera A, Stensel DJ (2013) Med Sci Sports Exerc. 45, 1261-1268. 